\title{
Gua Braholo: Karakter Hunian Mikro Pada Awal Kala Holosen Di Gunung Sewu
}

\section{Retno Handini; Harry Widianto}

Keywords: settlement, occupation, cave, spatial, karst, prehistory, character, description, culture

\section{How to Cite:}

Handini, R., \& Widianto, H. (1999). Gua Braholo: Karakter Hunian Mikro Pada Awal Kala Holosen Di Gunung Sewu. Berkala Arkeologi, 19(1), 21-39. https://doi.org/10.30883/jba.v19i1.790

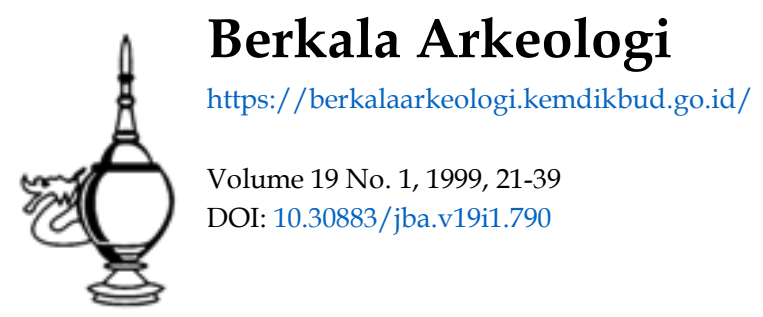

\section{(c) (1) (2) (2)}

This work is licensed under a Creative Commons Attribution-NonCommercial-ShareAlike 4.0 International License. 


\title{
GUA BRAHOLO : KARAKTER HUNIAN MIKRO \\ PADA AWAL KALA HOLOSEN DI GUNUNG SEWU
}

\author{
Retno Handini" \\ Harry Widianto ${ }^{*}$
}

Terletak di Desa Semugih, Kecamatan Rongkop, Kabupaten Gunung Kidul, Provinsi Daerah Istimewa Yogyakarta, Gua Braholo merupakan salah satu gua hunian prasejarah yang berada dalam jajaran pegunungan karst Gunung Sewu. Gua ini ditemukan oleh Bidang Prasejarah Pusat Penelitian Arkeologi Nasional, ketika dilakukan survei di seluruh wilayah Gunung Sewu pada tahun 1996. Belasan gua ditemukan di bagian barat pegunungan ini dan salah satu di antaranya adalah Gua Braholo, yang kemudian ditindaklanjuti dengan melaksanakan ekskavasi pada tahun 1997 dan 1998.

Gua ini menghadap ke barat daya $\left(\mathrm{N} 200^{\circ} \mathrm{E}\right)$, pada ketinggian 357 meter di atas permukaan laut. Bagian tengah gua dilihat dari berbagai sudut pandang sangat ideal untuk dijadikan sebagai hunian. Ruangan gua sangat lapang dengan langit-langit yang tinggi membentuk kubah, dengan luas lantai gua sekitar 600 meter persegi. Pintu gua yang lebar --39 meter-- dengan ketinggian mencapai 15 meter, membuat bagian dalam gua cukup terang dengan lantai gua yang sebagian relatif datar, dan umumnya kering. Memanjang arah timur laut-barat daya, bagian timur dan selatan lantai ini terisi oleh boulder-boulder runtuhan dari atap gua serta stalagmit.

Aspek keruangan tersebut membuat sirkulasi udara dan penyinaran sangat baik, ditambah dengan keletakan gua yang berada di lereng bukit sehingga gua ini mudah dicapai, menjadikan gua ini sangat berpotensi sebagai sebuah hunian yang ideal. Faktor lain yang menjadikan gua ini layak huni adalah (Handini, 1997a) : kelembaban udara dalam gua yang tidak terlalu tinggi, lantai gua yang relatif cukup kering, lokasi yang relatif dekat dengan sumber air, dan tersedianya sumber daya alam yang melimpah, baik untuk konsumsi makanan maupun bahan pembuatan alat.

\section{- Karakter Budaya Utama}

Menindaklanjuti penemuan gua dalam survei di tahun 1996, maka 2 kali penelitian yang lebih intensif dalam bentuk ekskavasi telah dilaksanakan oleh Pusat Penelitian Arkeologi Nasional, yang antara lain bekerja sama pula dengan Toyota Foundation

.. Pusat Penelitian Arkeologi Nasional

- Balai Arkeologi Yogyakarta

Berkala Arkeologi Th. XIX (1) 
dari Jepang. Dalam penelitian tersebut telah dibuka 8 (delapan) buah kotak ekskavasi yang berukuran $2 \times 2$ meter (yaitu kotak G6, J9, dan 08), dan berukuran $2 \times 1$ meter (yaitu kotak 17, K8, L8, M8, N8, dan 08)(Gambar 1). Ekskavasi tersebut menunjukkan hasil yang sangat menarik. Di samping sisa fauna darat dan laut yang sangat melimpah, ditemukan pula sisa industri litik yang padat, mulai dari serpih buangan, alat-alat yang dibuat dan peralatan untuk mengerjakan alat. Tampak pula pemanfaatan tulang-tulang dan tanduk binatang untuk dijadikan berbagai alat, demikian juga cangkang-cangkang moluska untuk perhiasan. Temuan yang lebih menarik adalah sisa manusia, berupa sisa kubur primer (di kotak J9) dan sisa kubur sekunder (di kotak L8).

Temuan-temuan di atas menunjukkan betapa pentingnya Gua Braholo dalam penelitian tentang hunian Kala Holosen untuk melengkapi data hunian Gunung Sewu. Ekskavasi yang dilakukan hingga tahun 1998 belum mencapai lapisan steril, bahkan nampak indikasi lapisan budaya yang masih terus berlanjut hingga ke lapisan Plestosen.

\section{- Stratigrafi Endapan Gua}

Sistem pengendapan tanah pada Gua Braholo dapat diketahui secara lengkap pada stratigrafi kotak G6 sebagai kotak yang paling dalam digali, mencapai kedalaman 759 $\mathrm{cm}$ di bawah permukaan tanah. Hasil pengamatan pada seluruh kotak ekskvasi menunjukkan bahwa sistem pengendapan tersebut telah terjadi secara lateral di seluruh permukaan gua, dengan variasi ketebalan, lapisan yang berbeda antara satu kotak dengan kotak ekskavasi lainnya. Dalam hal ini, stratigrafi kotak G6 merupakan stratigrafi yang paling lengkap bagi penjabaran stratigrafi endapan gua di situs ini, yang menunjukkan adanya 5 (lima) lapisan utama sebagai berikut (Handini, 1998) :

Lapisan la : Tanah warna coklat tua, gembur, teraduk, ketebalan maksimal $20 \mathrm{~cm}$

Lapisan Ib : Tanah warna coklat kemerahan, gembur, berbutir sedang, mengandung sisipan berupa pasir, ketebalan maksimal $30 \mathrm{~cm}$

Lapisan 2 : Tanah warna coklat, gembur berbutir sedang, mengandung sisa vertebrata, moluska, ketebalan maksimal $72 \mathrm{~cm}$

Lapisan 3 : Tanah warna putih keabu-abuan, banyak mengandung sisipan berupa abu pembakaran (perapian), sisa vertebrata, moluska, arang dan serpih, ketebalan maksimal $214 \mathrm{~cm}$

Lapisan 4a: Tanah warna hitam kecoklatan mengandung sisipan abu pembakaran, tanah terbakar, sisa vertebrata, moluska, arang dan serpih, ketebalan maksimal $80 \mathrm{~cm}$ 
Lapisan 4b : Tanah warna coklat kehitaman, gembur, berbutir sedang, mengandung sisa vertebrata, moluska, serpih dan blok batuan, ketebalan maksimal 84 $\mathrm{cm}$

Lapisan 5a: Tanah warna coklat kemerahan, padat, banyak mengandung sisa vertebrata, ketebalan maksimal $80 \mathrm{~cm}$

Lapisan 5b: Tanah warna coklat kehitaman, padat, banyak mengandung sisa vertebrata, ketebalan maksimal $140 \mathrm{~cm}$

Dalam krono-stratigrafi di atas, masih terdapat sisipan abu volkanis antara lapisan $4 \mathrm{a}$ dan 4 b setebal maksimal $24 \mathrm{~cm}$, dan antara lapisan 5a dan 5b setebal sekitar $6 \mathrm{~cm}$. Lapisan ini terlihat lebih banyak intensitas pengendapannya pada kotak 08, yang mencapai paling tidak 5 kali pengendapan abu volkanik pada lapisan 3. Di lain pihak, sisipan-sisipan lapisan abu yang berupa lensa juga ditemukan hampir di setiap kotak, mulai kedalaman sekitar $70 \mathrm{~cm}$ di bawah permukaan tanah (untuk kotak G6) hingga kedalaman sekitar $350 \mathrm{~cm}$. Oleh karena itu, dua jenis lapisan abu diperoleh pada kotak-kotak ekskavasi di situs ini, berasal dari aktivitas volkanik dan aktivitas manusia. Dalam posisi vertikal, komponen budaya Gua Braholo yang berupa alat batu, alat tulang, sisa fauna, dan sisa moluska tersebar mulai permukaan tanah hingga lapisan paling dalam di kotak G6.

\section{-Sisa Industri Litik}

Kegiatan industri litik berlangsung intensif di dalam gua, hal ini ditunjukan dengan adanya temuan litik dari berbagai tingkatan pengerjaan, yakni (Handini, 1997b) :

- Bahan-bahan mentah untuk pembuatan alat yang belum sempat dikerjakan, banyak ditemukan di dalam kotak-kotak gali.

- Produk industri berupa alat-alat (artefak) yang dihasilkan antara lain serut (serut samping, serut ujung, serut berpunggung tinggi), lancipan, bor, beliung persegi, batu asah, kapak perimbas, beliung penarah, batu pipisan dll.

- Batu-batu inti dengan tingkat pengerjaan yang bervariasi.

- Sisa pembuatan serpih berupa serpihan-serpihan yang tidak dikerjakan (debris).

Keempat unsur tahap pembuatan alat batu di atas memberikan gambaran tentang proses kegiatan industri yang meliputi tahapan pengerjaan secara lengkap, mulai dari pemangkasan awal berupa pelepasan serpih-serpih hingga terciptanya alat yang diinginkan, berserta serpihan-serpihannya. Pada umumnya batuan yang dikerjakan untuk pembuatan alat adalah jenis batuan chert, basalt, gamping, jasper, kalsit dll. Dari sekian banyak jenis batuan tersebut, nampaknya batu gamping adalah jenis batuan yang paling mudah diperoleh di sekitar gua. Kesulitan memperoleh batu "rijang" dan 
batuan silika lainnya di sekitar gua, menyebabkan batu gamping yang tersedia di sekitamya merupakan bahan yang cukup menonjol dalam "assemblage" litik. Dalam hal ini, aspek kekerasan atau kualitas batuan bukan lagi menjadi faktor penentu dalam pemilihan bahan. Batu gamping yang sifatnya lunak dan sulit dibentuk telah dimanfaatkan untuk peralatan. Keberadaan artefak litik dari batuan silika dan batuan lainnya di gua ini melalui proses pencarian bahan dari luar.

Temuan industri litik di Gua Braholo ini cukup dominan, baik jenis alat maupun jumlah temuannya. Analisis terhadap industri litik ini dari hasil ekskavasi tahun 1998 telah diperoleh data sbb (Handini, 1998):

\begin{tabular}{|c|c|c|c|c|c|c|c|c|c|}
\hline \multirow[t]{2}{*}{ Jenis alat } & \multicolumn{8}{|c|}{ Kotak } & \multirow[t]{2}{*}{$\mathbf{J m l}$} \\
\hline & G6 & J9 & 08 & I7 & $\mathbf{K 8}$ & L8 & M8 & N8 & \\
\hline Batu inti & - & - & 12 & - & - & - & 1 & 2 & 15 \\
\hline Serut cekung & 2 & 2 & 3 & - & 3 & - & 1 & 2 & 13 \\
\hline Serut ujung & 1 & $=$ & 10 & 1 & - & $=$ & 2 & 3 & 17 \\
\hline Serut samping & 1 & 3 & 35 & 1 & 9 & - & 4 & - & 53 \\
\hline Serut membulat (Disque) & - & - & 2 & - & - & - & $=$ & - & 2 \\
\hline Serut berpunggung tinggi & - & 1 & 1 & - & 1 & - & - & - & 3 \\
\hline Serut gigir & - & - & 1 & - & $=$ & - & - & 2 & 3 \\
\hline $\begin{array}{l}\text { Serpih dengan retus } \\
\text { pemakaian }\end{array}$ & 1 & 4 & 116 & - & 9 & - & 5 & 9 & 144 \\
\hline Serpih tanpa retus & 14 & 63 & 1954 & 61 & 277 & 63 & 130 & 128 & 2690 \\
\hline $\begin{array}{l}\text { Bilah dengan retus } \\
\text { pemakaian }\end{array}$ & - & 1 & 5 & - & 1 & 4 & 6 & - & 17 \\
\hline Bilah tanpa retus & - & 1 & 101 & - & - & - & - & - & 102 \\
\hline Pisau & - & 1 & 1 & - & - & - & - & - & 2 \\
\hline Lancipan & - & - & 1 & - & 2 & $=$ & - & $\cdot$ & 3 \\
\hline Lancipan bertangkai & - & - & 1 & - & - & - & 1 & 1 & 3 \\
\hline Bor & $=$ & - & 1 & - & 2 & $=$ & - & - & 3 \\
\hline Mata panah & - & - & 5 & - & 1 & - & 1 & - & 7 \\
\hline Hematit & - & 1 & 14 & - & 14 & 7 & 5 & 4 & 45 \\
\hline Fossil kayu & - & $=$ & 1 & - & - & - & - & $=$ & 1 \\
\hline Debris & 14 & 61 & 2169 & 19 & 233 & 94 & 120 & 144 & 2854 \\
\hline Batuan & 6 & 11 & 251 & 156 & 106 & 106 & 132 & 313 & 1081 \\
\hline Total & 39 & 151 & 4695 & 238 & 656 & 276 & 408 & 610 & 7073 \\
\hline
\end{tabular}

Industri litik yang paling dominan dari gua ini adalah alat serpih-bilah (Gambar 2), dengan tipologinya cukup beragam, antara lain serut (serut samping, serut ujung, serut gigir, serut berpunggung tinggi, serut cekung), lancipan, bor, serpih dengan bekas pemakaian dll. Selain serpih dan bilah, beberapa jenis artefak litik lainnya juga 
ditemukan dalam eksakavasi ini dalam jumlah kecil, antara lain batu pipisan, batu pelandas, batu giling dan batu asah.

Persebaran artefak litik di Gua Braholo tidak merata. Di bagian tertentu dari ruangan gua menunjukkan kandungan temuan yang sangat padat, sementara di bagian lainnya lebih jarang. Dari persebaran tersebut dapat diketahui bahwa bagian gua dimana konsentrasi artefak ditemukan merupakan lokasi kegiatan industri. Dibanding kotakkotak gali lain, kotak 08 yang terletak di bagian timur dari ruangan gua merupakan kotak dengan temuan litik yang paling besar, dengan tingkat pengerjaan dan jenis yang paling bervariasi. Nampaknya kotak ini dimanfaatkan untuk lokasi bengkel dengan menggunakan bahan dasar berbagai macam batu kersikan dan batu gamping.

\section{-Industri Alat-alat Tulang}

Satu keistimewaan temuan di Gua Braholo ini adalah ditemukannya bermacammacam alat terbuat dari tulang di semua kotak ekskavasi dengan variasi jenis, bentuk dan ukuran yang bermacam-macam dalam jumlah cukup besar. Dari hasil analisis yang dilakukan oleh Drs. Bagyo Prasetyo M.Hum, diperoleh data mengenai jenis dan jumlah alat-alat tulang hasil ekskavasi Gua Braholo tahun 1998 seperti ditunjukkan dalam tabel di bawah ini (Handini, 1998):

\begin{tabular}{|c|c|c|c|c|c|c|c|c|}
\hline \multirow[t]{2}{*}{ No } & \multirow[t]{2}{*}{ Jenis Temuan } & \multicolumn{6}{|c|}{ Kotak } & \multirow[t]{2}{*}{ Jml } \\
\hline & & 08 & 17 & K8 & L8 & M8 & N8 & \\
\hline A. & Spatula & & & & & & & \\
\hline 1. & Spatula bifasial & - & - & 1 & 1 & 3 & - & 5 \\
\hline 2. & Spatula tajaman tidak jelas & - & - & - & - & 1 & - & 1 \\
\hline 3. & Spatula monofasial & 1 & 1 & 4 & 1 & 5 & 4 & 16 \\
\hline B. & Lancipan & & & & & & & \\
\hline 1. & Lancipan ganda monolateral & - & 1 & - & - & - & - & 1 \\
\hline 2. & Lancipan tunggal monolateral & 1 & 2 & 15 & - & 6 & 1 & 25 \\
\hline 3. & Lancipan tunggal bilateral & - & - & 3 & - & 1 & - & 4 \\
\hline C. & Jarum & & & & & & & \\
\hline 1. & Jarum tunggal monolateral & 1 & 3 & 20 & 1 & 12 & 2 & 39 \\
\hline 2. & Jarum tunggal bilateral & - & - & 1 & - & 1 & 1 & 3 \\
\hline 3. & Jarum ganda monolateral & $=$ & 3 & 1 & - & 3 & 1 & 8 \\
\hline 4. & Jarum dengan pangkasan tidak jelas & - & - & - & - & 1 & - & 1 \\
\hline D. & Lain-lain & & & & & & & \\
\hline 1. & Tulang dipangkas & 3 & - & 2 & - & - & - & 5 \\
\hline 2. & Calon spatula & 1 & - & - & - & - & - & 1 \\
\hline 3. & Serut & - & - & 1 & $=$ & - & - & 1 \\
\hline 4. & Alat upam & - & - & 1 & - & - & - & 1 \\
\hline & Jumlah & 7 & 10 & 49 & 3 & 33 & 9 & 111 \\
\hline
\end{tabular}


Segi-segi teknologi tulang menunjukkan penguasaan teknologi yang sudah sangat maju, dari penerapan teknik yang paling sederhana yaitu teknik pecah sederhana, hingga pada teknik pangkas, teknik selumbar, dan teknik belah. Pemecahan, pemangkasan (bagian proksimal, distal, ataupun keduanya), serta pembelahan merupakan teknologi awal yang diterapkan, yang kemudian diikuti dengan proses penggosokan untuk membentuk artefak sesuai dengan keperluan. Oleh karena itu, penerapan berbagai teknik pengerjaan alat tulang tersebut telah menghasilkan tipe-tipe alat yang cukup bagus dan halus (Gambar 3). Tipe-tipe utamanya adalah lancipan, jarum, dan spatula, dengan berbagai tipe yang lebih spesifik dari masing-masing tipe utama tersebut (periksa pula Bagyo Prasetyo, dalam volume ini).

\section{- Sisa Fauna}

Eksploitasi sumber daya fauna dalam kehidupan di Gua Braholo tampak jelas dari temuan sisa fauna yang sangat padat. Jenis moluska ditemukan cukup menonjol baik dalam bentuk alat, perhiasan maupun cangkang biasa. Jenis-jenis moluska yang ditemukan dalam ekskavasi gua Braholo tahun 1998 adalah (Handini, 1998) :

\begin{tabular}{|l|l|l|l|}
\hline \multicolumn{1}{|c|}{ FAMILI } & \multicolumn{1}{|c|}{ GENUS } & \multicolumn{1}{c|}{ SPESIES } & HABITAT \\
\hline GASTROPODA & & & \\
\hline Pleurodontidae & Amphidromus & Amphodromus heerianus & Darat \\
\hline & & Amphidromus inversus & Darat \\
\hline & & Amphidromus alticola & Darat \\
\hline & Landouria & Landouria rotatoria & Darat \\
\hline & Pseudopartula & Pseudopartula galericulum & Darat \\
\hline Cyclophoridae & Cyclotus & Cyclotus discoideus & Darat \\
\hline & Lagochilus & Lagochilus ciliferum & Darat \\
\hline & Cycloporus & Cycloporus perdix & Darat \\
\hline & Leptopoma & Leptopoma vitreum & Darat \\
\hline Helicarionidae & Elaphroconcha & Elaphroconcha bataviana & Darat \\
\hline & Dyakia & Dyakia rumphii & Darat \\
\hline & & Dyakia clypeus & Darat \\
\hline Achatinidae & Achatina & Achatina fulica & Darat \\
\hline Zonitinidae & Trochomorpha & Trochomorpha planorbis & Darat \\
\hline Thiaridae & Brotia & Brotia testudinaria & Air tawar \\
\hline Haliotidae & & & Laut \\
\hline Patellidae & Patella & & Laut \\
\hline Neritidae & Nerita & & Laut \\
\hline Turbinidae & & & Laut \\
\hline Cypraeidae & & Polinices mamilla & Laut \\
\hline Naticidae & Polinices & Mancinella bufo & Laut \\
\hline Muricidae & Mancinella & & \\
\hline & & & \\
\hline
\end{tabular}




\begin{tabular}{|l|l|l|l|}
\hline PELECYPODA & & & \\
\hline Unionidae & Rectidens & Rectidens sumatrensis & Air tawar \\
\hline & Contradens & Contradens contradens & Air tawar \\
\hline Corbiculidae & Polymesoda & Polymesoda coaxan & Air payau \\
\hline Veneridae & Venus & & Laut \\
\hline & Tapes & Tapes striata & Laut \\
\hline Arcidae & Anadara & Anadara antiquata & Laut \\
\hline Donacidae & Donax & Donax sp. & Laut \\
\hline Mytilidae & Perna & Perna viridus & Laut \\
\hline NAUTILUS & & & \\
\hline
\end{tabular}

Sisa-sisa fauna di luar moluska, berupa tulang-tulang yang masih utuh maupun fragmentaris, tengkorak, rahang, gigi, dan tanduk ditemukan sangat melimpah di semua kotak ekskavasi. Jenis-jenis fauna yang pernah hidup atau dimanfaatkan di daerah ini antara lain adalah (Handini, 1998) :

\begin{tabular}{|l|l|l|}
\hline \multicolumn{2}{|c|}{ Filum Vertebrata } & \multicolumn{1}{|c|}{ Kelas Reptilia } \\
\hline Kelas Mamalia & Kelas Aves \\
\hline Chiropteridae (kalong) & Ophidia (ular) & Gallidae (ayam) \\
\hline Canidae (anjing hutan) & Boridae (ular sanca/python) & \\
\hline Viveridae (musang) & Testudinidae (kura-kura) & \\
\hline Mustelidae (linsang) & & \\
\hline Muridae (tikus) & & \\
\hline Hystricidae (landak) & & \\
\hline Sciuridae (tupai) & & \\
\hline Bovidae (kerbau, sapi, banteng) & & \\
\hline Cervidae (rusa) & & \\
\hline Tragulidae (kancil) & & \\
\hline Suidae (babi hutan) & & \\
\hline Hippopotamidae (kuda nil) & & \\
\hline Rhinoceridae & & \\
\hline Elephantidae (gajah) & & \\
\hline Macaca sp (monyet) & & \\
\hline Homo Sapiens (manusia) & & \\
\hline
\end{tabular}

Tulang-tulang dari Macaca sp. (monyet) ditemukan sangat dominan di seluruh kotak yang digali, baik secara vertikal maupun horisontal, dan situasi ini membuktikan adanya perburuan khusus jenis binatang ini pada waktu itu. Lebih jauh lagi, teridentifikasi dari situs ini bahwa mikro fauna -termasuk monyet-- lebih banyak mendominasi bagian atas, sementara makro fauna -misalnya Cervidae dan Bovidaemendominasi bagian bawah endapan gua. Sisa fauna yang ditemukan sangat melimpah di Gua Braholo ini dalam kaitannya dengan konteks budaya dan hunian, menunjukkan kaitan yang kuat dengan manusia penghuni gua tersebut. Fauna-fauna 
tersebut kemungkinan diperoleh dari perburuan di sekitar gua. Ditemukannya moluska laut, baik dari jenis Gastropoda, Pelecypoda maupun Cephalopoda mungkin dapat menunjukkan bahwa areal eksploitasi mereka mencapai daerah pesisir.

\section{- Sisa Manusia}

Hingga penelitian di tahun 1998, telah ditemukan 2 (dua) individu manusia di situs hunian gua prasejarah ini (Widianto, 1999). Pada lapisan perapian di kotak J9, ditemukan sebuah rangka manusia yang cukup lengkap dalam konteks temuan artefak batu dan sisa fauna, yang merupakan bagian dari sistem penguburan primer. Pertanggalan C-14 pada level rangka menghasilkan angka $9780 \pm 230$ BP (Simanjuntak, 1998). Individu kedua merupakan sisa rangka dari sistem penguburan sekunder, ditemukan pada kotak L8, pada lapisan perapian yang sama dengan individu pertama, tetapi posisinya lebih tinggi sekitar $50 \mathrm{~cm}$ dibandingkan dengan individu pertama. Pertanggalan yang dihasilkan untuk level rangka individu kedua adalah $8.760 \pm 170 \mathrm{BP}$.

Individu pertama merupakan sisa rangka dengan posisi telentang, kedua kaki terlipat ke atas (Gambar 4). Posisi anatomisnya menunjukkan letak kepala di sebelah barat, sementara bagian anggota badan bawah (kaki) ada di sebelah timur. Kedua tangan terjulur relatif lurus ke bagian bawah dengan telapak tangan bertumpu di atas lutut. Beberapa batu menutup bagian dada dan kaki.

Sisa rangka relatif masih utuh, sebagian besar masih terwakili bagian-bagian anatomisnya, meski sudah ada yang hilang atau rusak. Tengkorak telah pecah menjadi beberapa fragmen, maxilla sebagian terkonservasi yang dilengkapi dengan gigi-gigi atas dalam ukuran besar. Arcus alveolaris menunjuk pula pada maxilla ukuran besar, dengan palatin yang lebar dan dalam, dan mengindikasikan prognatisme menonjol. Dari rahang bawahnya, terlihat karakternya yang sangat kekar, dengan corpus mandibularis yang tinggi dan tebal. Di bagian symphysis, sisi lingual, terdapat planum alveolaris, dan di pertengahan tingginya melintang seeara jelas torus mandibularis. Kedua ciri pada muka lingual tersebut merupakan ciri arkaik yang umum terdapat di kalangan Homo erectus, dan sangat jarang terdapat di kalangan Homo sapiens. Alveolaris mandibula sangat tebal, lebih tebal dibandingkan dengan bagian basilarisnya. Implikasinya, gigi-geligi menjadi demikian besar, yang bersama-sama ciri lainnya, membuat rahang bawah individu ini menjadi demikian kekar. Hal ini selaras dengan ukuran tulang-tulang panjang yang tergolong besar.

Tulang tangan -humerus, ulna, maupun radius - kanan dan kiri masih terkonservasi baik, sementara tulang telapak tangan (metacarpal dan phalanx) yang tertinggal 
hanyalah bagian kirinya saja. Bagian kanan mungkin telah terangkat dalam proses penggalian. Kedua kaki terlipat ke atas, lutut di bagian atas dan condong ke kanan. Bagian distal femur kiri dan bagian proksimal fibula kiri telah patah, sementara kedua patella telah hilang. Sebuah batu menutup bagian telapak kaki, dengan tarsal, metatarsal, dan phalanx kaki kiri yang relatif masih berada pada susunan anatomisnya. Beberapa phalanx kanan terpisah dari telapak tangannya dan menyebar di bagian selatan rangka.

Tulang rusuk (costae) yang tampak baru bagian kiri, yang terkumpul antara vertebrae dan humerus kiri. Di lain pihak, empat buah vertebrae telah terekspose dalam susunan anatomisnya, yang seluruhnya merupakan bagian dari vertebrae thoracicae. Lebih ke bawah, hanya coxa kiri yang terekspose dalam keadaan relatif utuh, sementara coxa kanan masih tertutup tangan.

Dari coxa kiri diperoleh karakter morfologis sebagai berikut : cavitas pelvis sempit, bentuk coxa ramping dan memanjang secara infero-superior, dengan incisura sciatica major sempit, dan foramen obturatum memanjang. Ciri-ciri morfologis ini menunjukkan individu laki-laki, yang diperkuat oleh ukuran maxilla, mandibula, dan gigi-geligi yang kekar. Di lain pihak, fragmen tangkorak dan ukuran tulang secara menyeluruh termasuk besar.

Gigi-geligi, baik gigi atas maupun bawah, relatif masih lengkap. Susunan gigi menunjukkan telah erupsinya M3 secara sempurna, dengan permukaan oklusal yang telah cukup berkembang. Situasi ini menjelaskan bahwa individu ini telah melewati usia 18 tahun, termasuk ke adalam individu dewasa. Pengamatan secara lebih seksama terhadap tingkat keausan gigi pada gigi geraham menunjukkan keausan hingga mencapai dentin tetapi belum mencapai covum pulpae, sehingga menunjukkan tingkat keausan tiga pada skala Broca. Situasi ini memberikan gambaran mengenai individu yang telah melewati usia 50 tahun. Oleh karena itu, disimpulkan bahwa rangka ini merupakan individu dewasa yang telah melewati usia 50 tahun.

Individu kedua dari Situs Song Braholo berasal dari kotak L8, hasil ekskavasi bulan Oktober 1998, dalam suatu lapisan sisa abu perapian. Tidak terdapat unsur tulang manusia lainnya kecuali tengkorak dan pinggul, sehingga sisa rangka ini merupakan bagian dari teknik penguburan sekunder. Ditemukan dalam posisi terbalik, tengkorak dan komponen tulang pinggul ini berasosiasi secara kuat dengan sebaran tulang-tulang mamalia kecil, terutama dari jenis Macaca sp. Beberapa artefak tulang, antara lain dalam bentuk spatula, juga ditemukan di sekitarnya.

Status penguburan sekunder sangat kuat bagi sisa manusia ini. Hanya tengkorak (termasuk rahang bawahnya), tulang pinggul (coxa) kanan, dan tulang ekor (sacrum) saja yang ditemukan, dalam posisi saling berhimpitan. Keadaan tengkorak sudah 
pecah terhimpit beban pasca-mortem, meski pecahan-pecahan tulangnya masih berada pada posisi awalnya, sementara keadaan tulang pinggul dan tulang ekornya lebih baik terkonservasi. Rahang bawah, terutama corpus dan ramus bagian kiri telah terlepas, sementara bagian kanan masih menyatu dengan rahang atas, kedua permukaan oklusalnya masih bertaut. Bagian symphysis rahang bawah beserta gigi-gigi seri bawahnya telah hilang. Di bagian leher, masih tersisa dua vertebrae paling atas, bagian dari vertebrae cervicalus.

Kesan pertama dari tengkorak ini adalah bentuknya yang memanjang (dolicocephal), dengan prognatisme menonjol. Tonjolan keningnya terlihat, terutama pada bagian arcus superciliaris, tetapi tidak terlalu kuat. Linea temporalis yang terlihat untuk sementara adalah pada bagian frontal, yang kemudian menyatu dengan bagian pelipis. Sebagian besar karakter morfologis tengkorak masih tertutup tanah, termasuk di dalamnya adalah sutura yang ada, kecuali sebagian sutura lambdoidea bagian kiri yang belum menunjukkan sinostose lanjut. Pars orbitalis pada squama frontalis terlihat lancip dengan perkiraan bentuk orbit yang bundar. Sementara, planum nuchalis pada os occipital tampak halus, insersi otot tidak berkembang.

Memiliki maxilla yang kekar, arcus supercialis masih relatif utuh terkonservasi. Palatin lebar dan dalam. Gigi-geligi bagian kiri lengkap, sementara di bagian kanan hanya dapat ditemukan $\mathrm{C}, \mathrm{P} 2, \mathrm{M} 1$ dan $\mathrm{M} 2$, dalam ukuran besar. Tingkat keausan gigi sudah sangat lanjut, mencapai cavrum pulpae (tingkat keausan derajad keempat), dengan menyisakan sedikit mahkota gigi saja. Bagian paling aus terdapat pada daerah gigi taring dan prageraham. Corpus mandibularis lebih rendah dibandingkan dengan sisa rangka pada kotak $\mathrm{J}$, dengan bagian alveolaris mandibulanya jauh lebih tebal dibandingkan bagian basilarisnya. Planum alveolaris yang terlihat jelas pada rangka kotak J9 tidak terlihat pada individu ini, sementara torus mandibularis tampak kuat melintang di bawah posisi foramen mentalis (Gambar 5). Meski secara individual terlihat bahwa mandibula sisa manusia ini secara signifikan lebih rendah dan lebih ramping dibandingkan dengan individu dari kotak $\mathrm{J} 9$, namun relief-reliefnya, baik pada muka buccal maupun pada muka lingual, cukup baik berkembang. Secara keseluruhan, alat-alat mastikasi pada individu ini tergolong kekar.

Diwakili oleh coxa kanan dan sacrum yang masih pada posisi anatomisnya, terkesan bahwa pelvis dari individu ini lebar dan terbuka. Konotasi lebar tersebut dapat pula diamati pada ukuran coxa dan sacrum secara terpisah, dengan cavitas pelvis dan incisura sciata major yang juga lebar. Dengan melihat ciri-ciri morfologis tengkorak dan tulang pinggul pada individu ini, diketahui bahwa sisa rangka ini mewakili individu perempuan. Tingkat erupsi dan keausan gigi menunjuk pada individu dewasa lanjut, dengan usia lebih dari 50 tahun. 
Meski tidak terlalu lengkap, karakter morfologis yang terdapat pada dua individu sisa manusia di Gua Braholo cukup representatif bagi penentuan jenis rasnya. Fragmenfragmen tulang tengkorak dari individu pertama sangat tebal, dengan tonjolan di bagian occipitalnya. Di lain pihak, bentuk tengkorak memanjang (dolichocephal) sangat kuat ditunjukkan oleh individu kedua, sementara ciri muka dengan progathisma menonjol juga dimiliki oleh kedua individu tersebut. Rahang atas mempunyai langitlangit yang lebar dan dalam, yang menunjuk pada maxilla ukuran besar. Pada rahang bawah, corpus mandibularisnya sangat tebal, dengan bagian alveolaris yang lebih tebal dibandingkan dengan bagian basilarisnya. Kekekaran dari rahang bawah tersebut juga dikuatkan oleh berkembangnya torus mandibularis pada kedua individu, sementara planum alveolaris terlihat jelas pada individu pertama. Ukuran gigi-geligi sangat besar, jauh lebih besar dibandingkan dengan manusia sekarang.

Dengan mencermati karakter morfologis dari bagian kranio-fasial kedua individu tersebut, maka ciri-ciri ras Austromelanesid merupakan karakter dominan. Karakter ras Austromelanesid tersebut juga ditampakkan dari postur tubuh dan ukuran tulang pada individu pertama. Dalam lingkup yang lebih luas, ciri yang sama juga dimiliki oleh 4 (empat) individu pertama dari Song Keplek di Punung (Pacitan)(Handini dan Widianto, 1998). Data sisa rangka dari beberapa situs gua hunian prasejarah menunjukkan bahwa ras Austromelanesid lebih mempratekkan sistem penguburan terlipat dibandingkan dengan sistem penguburan telentang lurus, yang lebih sering dipraktekkan oleh ras Mongoloid.

\section{- Gua Braholo Sebagai Hunian Multi Fungsi}

Daerah Gunung Sewu dengan pegunungan karst dan lembah-lembah sempit serta dialiri banyak sungai ternyata menyimpan berbagai sisa kehidupan dari awal Kala Holosen, sesaat setelah berakhimya Jaman Es yang terakhir sekitar 11.000 tahun silam.. Keadaan geografis yang unik tersebut telah menyediakan sumberdaya alam melimpah, sehingga manusia tertarik untuk memanfaatkan dan mengeksploitasinya. Ribuan bukit karst yang tersebar memungkinkan terbentuknya gua-gua atau ceruk alam yang cocok untuk hunian (Simanjuntak, 1996). Gua-gua atau ceruk-ceruk alam ini sangat penting sebagai tempat tinggal yang aman, yang akan melindungi penghuni gua dari iklim atau cuaca yang tidak baik ataupun dari serangan binatang buas.

Indikator sebuah hunian yang baik adalah tempat dan ruang gerak yang nyaman, dekat dengan sumber air, dan lingkungan yang menyediakan sumberdaya fauna maupun flora serta sumber bahan baku yang cukup. Syarat-syarat ini rupanya dipenuhi oleh Gua Braholo, sehingga menjadikan gua ini sangat ideal untuk dihuni. Tersedianya sumber air, sumber daya fauna maupun flora memungkinkan penghuni gua untuk tetap survive. Sementara, tersedianya sumber bahan baku pembuatan alat 
baik litik maupun fauna mendorong berkembangnya kemahiran dalam industri pembuatan alat.

Eksploitasi sumber daya fauna tidak terbatas pada fauna darat, tetapi juga eksploitasi biota marin. Hal ini ditunjukkan oleh adanya beberapa temuan moluska laut dari kelas Gastropoda, Pelecypoda maupun Cephalopoda. Hal yang sangat menarik adalah ditemukannya beberapa perhiasan yang terbuat dari cangkang moluska. Cangkang tersebut dibentuk sedemikian rupa, dimana di sekeliling cangkang terdapat goresangoresan yang halus, sedangkan di bagian tengahnya terdapat satu atau dua lubang yang sengaja dibuat. Keberadaan perhiasan ini merupakan salah satu bukti bahwa manusia penghuni gua Braholo ini telah mengenal aspek estetis.

Selain subsitensi perburuan yang telah berlangsung sejak hunian gua, tampaknya dikenal juga subsistensi pemanfaatan biji-bijian, tetapi jauh lebih kemudian. Data stratigrafis menunjukkan bahwa temuan biji-bijian terdapat pada lapisan yang lebih muda, yaitu di atas lapisan 3, antara lain dari jenis kemiri (Aleurites moluccan) dan kenari (Canarium sp), yang umumnya ditemukan dalam keadaan terbakar atau hangus. Penemuan biji-bijian ini, walaupun dalam jenis dan jumlah yang terbatas, mengindikasikan adanya eksploitasi biji-bijian dalam alimentasi mereka.

Dari berbagai jenis temuan dan komposisi sebaran yang diuraikan di atas, tampak adanya beberapa jenis kegiatan yang berlangsung di Gua Braholo. Kegiatan yang cukup menonjol adalah industri pembuatan alat-alat batu dan alat-alat tulang dengan berbagai macam produk yang dihasilkan. Di samping kegiatan industri, Gua Braholo juga terbukti sebagai hunian atau tempat tinggal. Adanya temuan sisa fauna dari berbagai jenis, sisa industri, sisa pembakaran dan temuan lainnya mengindikasikan bahwa keberadaannya disebabkan oleh aktivitas manusia yang berlangsung secara permanen di dalam gua. Keberadaan sisa pembakaran di setiap kotak ekskavasi, khususnya kotak J9, di mana lapisan perapiannya mencapai 25 level, mengindikasikan adanya kegiatan perapian intensif yang telah berlangsung dalam waktu yang sangat lama. Di lain pihak, bagian tengah atau dalam gua merupakan lokasi penguburan, yang ditunjukkan oleh temuan sisa manusia di kotak $\mathbf{3 9}$ (kubur primer) dan di kotak L8 (kubur sekunder).

Seperti juga halnya dengan Song Keplek di Punung (Pacitan)(Handini dan Widianto, 1998), Gua Braholo menupakan salah satu situs hunian gua prasejarah di jajaran Gunung Sewu, yang mempunyai ciri spesifik. Pemanfaatan ruang di Gua Braholo mirip dengan Song Keplek, tetapi lebih kompleks dan bervariasi. Gua dengan ruang tinggal yang luas ini agaknya dihuni oleh suatu komunitas yang lebih besar dengan berbagai jenis aktivitas. Akumulasi jenis temuan pada setiap kotak ekskavasi menyiratkan adanya spesialisasi jenis industri. Bagian depan gua (mendekati mulut gua, bagian barat daya) dengan temuan artefak batu gamping yang padat (termasuk 
alat-alat masif), agaknya digunakan sebagai tempat industri pembuatan alat-alat batu gamping. Sementara, bagian arah timur laut teras gua, tampaknya digunakan untuk pembuatan industri tulang, khususnya jarum lancipan ganda. Di bagian baratnya, cenderung dipakai sebagai tempat pembuatan jarum lancipan tunggal. Asumsi ini didasarkan pada sebaran temuan yang sangat menonjol untuk jenis-jenis tersebut di setiap kotak ekskavasi. Di lain pihak, bagian paling timur dan paling dalam dari ruangan gua (permukaan yang paling rendah), agaknya digunakan untuk kegiatan industri pembuatan alat-alat batu dari bahan kersikan yang didatangkan dari luar daerah Braholo. Pada bagian ini, artefak dari batu gamping hampir tidak ditemukan, selain artefak dari bahan kersikan (Simanjuntak, 1998). Sementara, bagian tengah merupakan lokasi perapian yang cukup luas, memanjang di bagian utara mendekati dinding gua. Sesaat setelah kegiatan berhenti, sebagian dari areal ini dimanfaatkan pula sebagai lokasi penguburan, baik sebagai penguburan primer maupun sekunder. Bagaimana pun, asumsi ini masih harus dibuktikan pada penelitian mendatang, melalui pembukaan kotak-kotak ekskavasi secara sporadis di seluruh permukaan lahan gua.

Terimakasih disampaikan kepada Dr. Truman Simanjuntak, Kepala Bidang Prasejarah Pusat Penelitian Arkeologi Nasional, yang telah mengijinkan pemanfaatan data mutakhir bagi penulisan makalah ini. 


\section{KEPUSTAKAAN}

Handini, Retno, 1997a. Gua Braholo : Sebuah Gua Hunian Ideal pada Masa Lalu, Cinandi.

Yogyakarta : Panitian Lustrum VU Jurusan Arkeologi Fakultas Sastra UGM.

Handini, Retno, 1997b, Laporan Penelitian Gua Braholo (Tahap I). Jakarta : Bidang Prasejarah Pusat Penelitian Arkeologi Nasional. Tidak diterbitkan.

Handini, Retno, 1998. Ekskavasi Gua Braholo (Tahap II), Laporan Penelitian Arkeologi. Jakarta: Pusat Penelitian Arkeologi Nasional, tidak diterbitkan.

Handini, R., \& Widianto, H. (1998). Song Keplek: Okupasi Intensif Manusia Pada Periode PascaPlestosen Di Gunung Sewu. Berkala Arkeologi, 18(2), 72-91. https://doi.org/10.30883/jba.v18i2.785

Prasetyo, B. (1999). Artefak Tulang Situs Gua Babi (Kalimantan Selatan): Variasi Tipologis Dan Teknologisnya. Berkala Arkeologi, 19(1), 40-52. https://doi.org/10.30883/jba.v19i1.791

Simanjuntak, Truman, I 996. Pegunungan Seribu : Sejarah Hunian yang Panjang, kertas kerja pada Ceramah Ilmiah di Pemda Pacitan.

Simanjuntak, Truman (editor), 1998, Gunung Sewu : Ekploitasi pada Kala Holosen. Jakarta : in-press.

Widianto, Harry, 1999. Manusia Penghuni Gunung Sewu, dalam Simanjuntak (editor), Gunung Sewu : Eksploitasi pada Kala Holosen. Jakarta : inpress. 


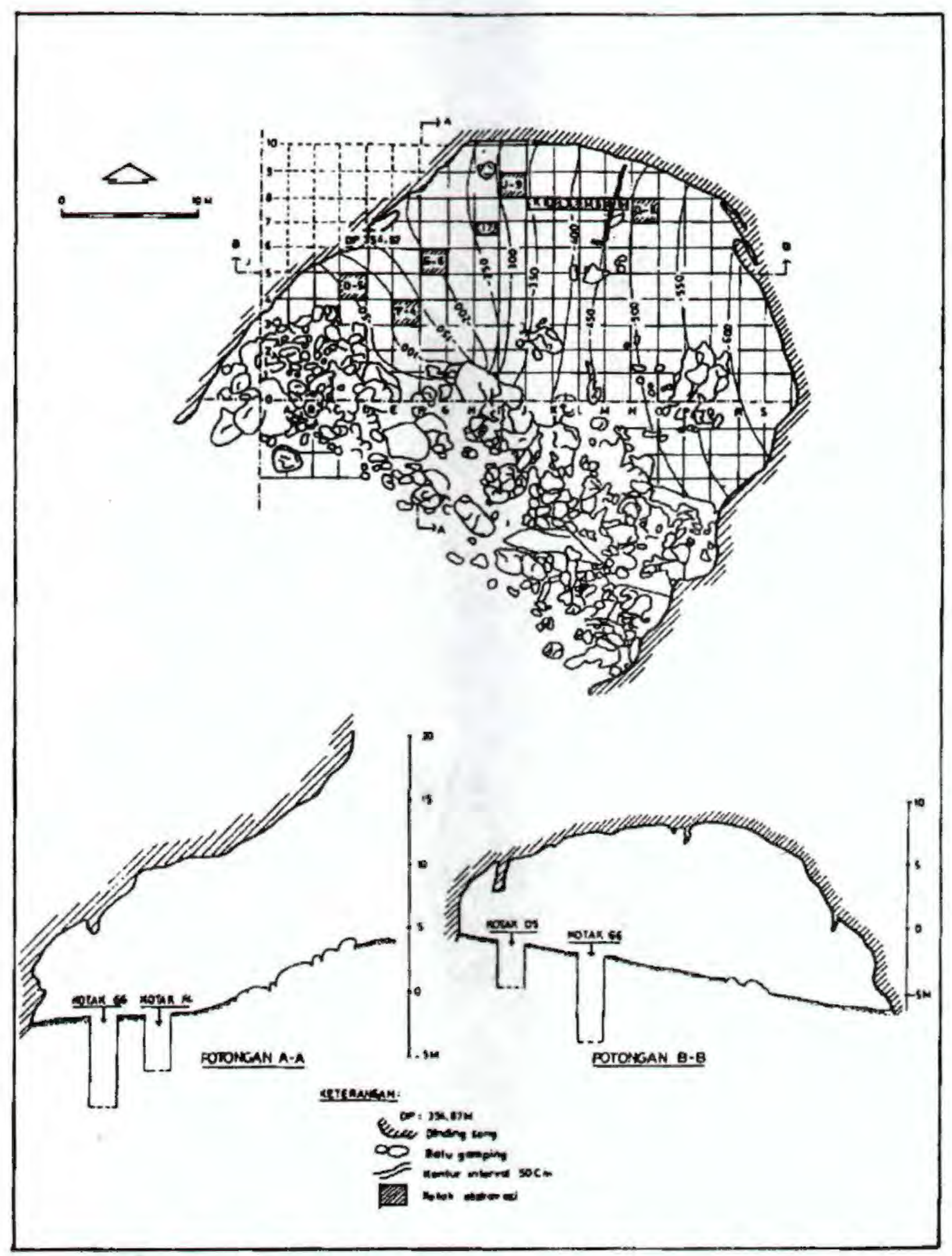

Gambar 1. Denah dan Irisan Gua Braholo 

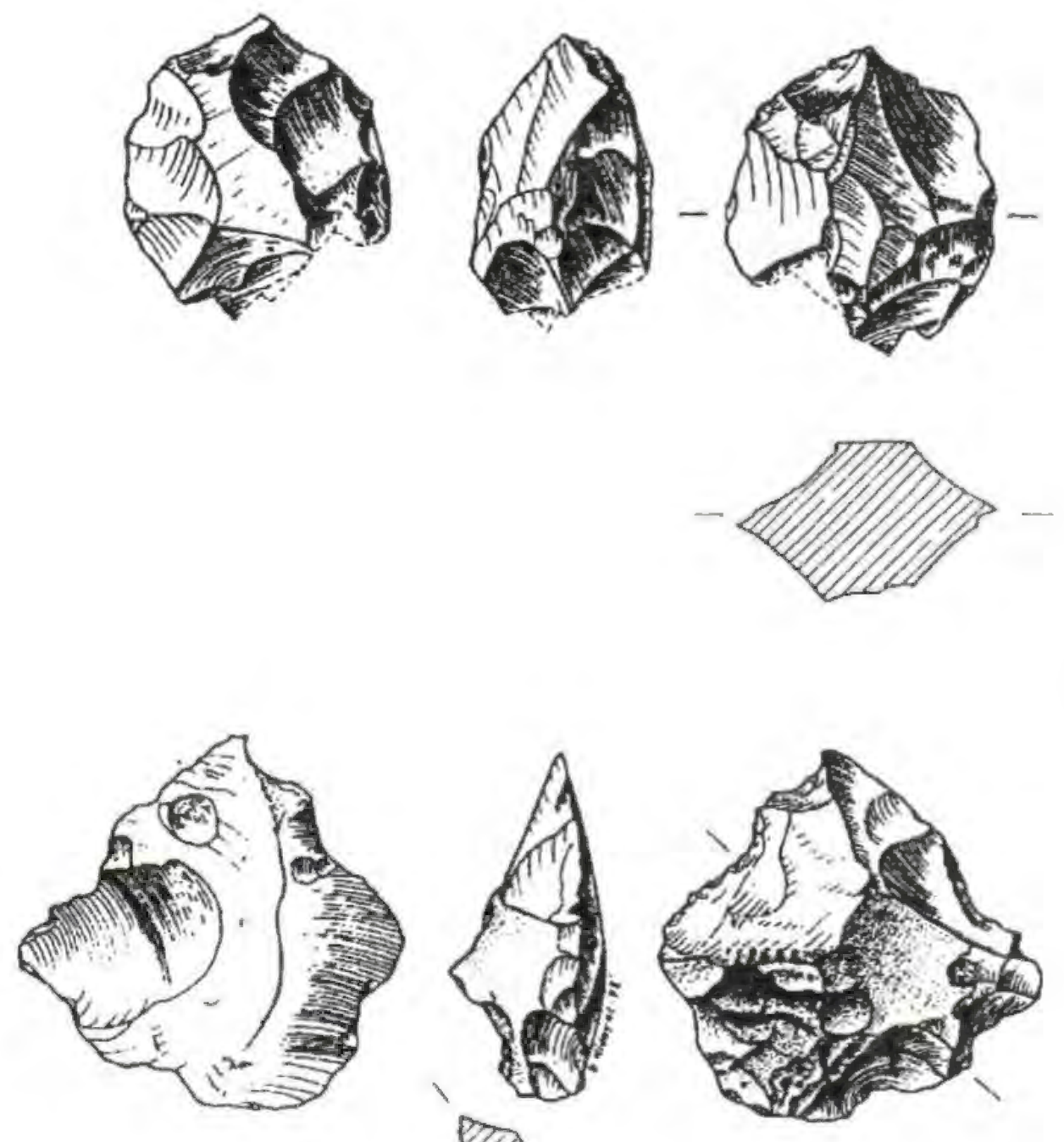

Gambar 2. Contoh alat serpih Gua Braholo 

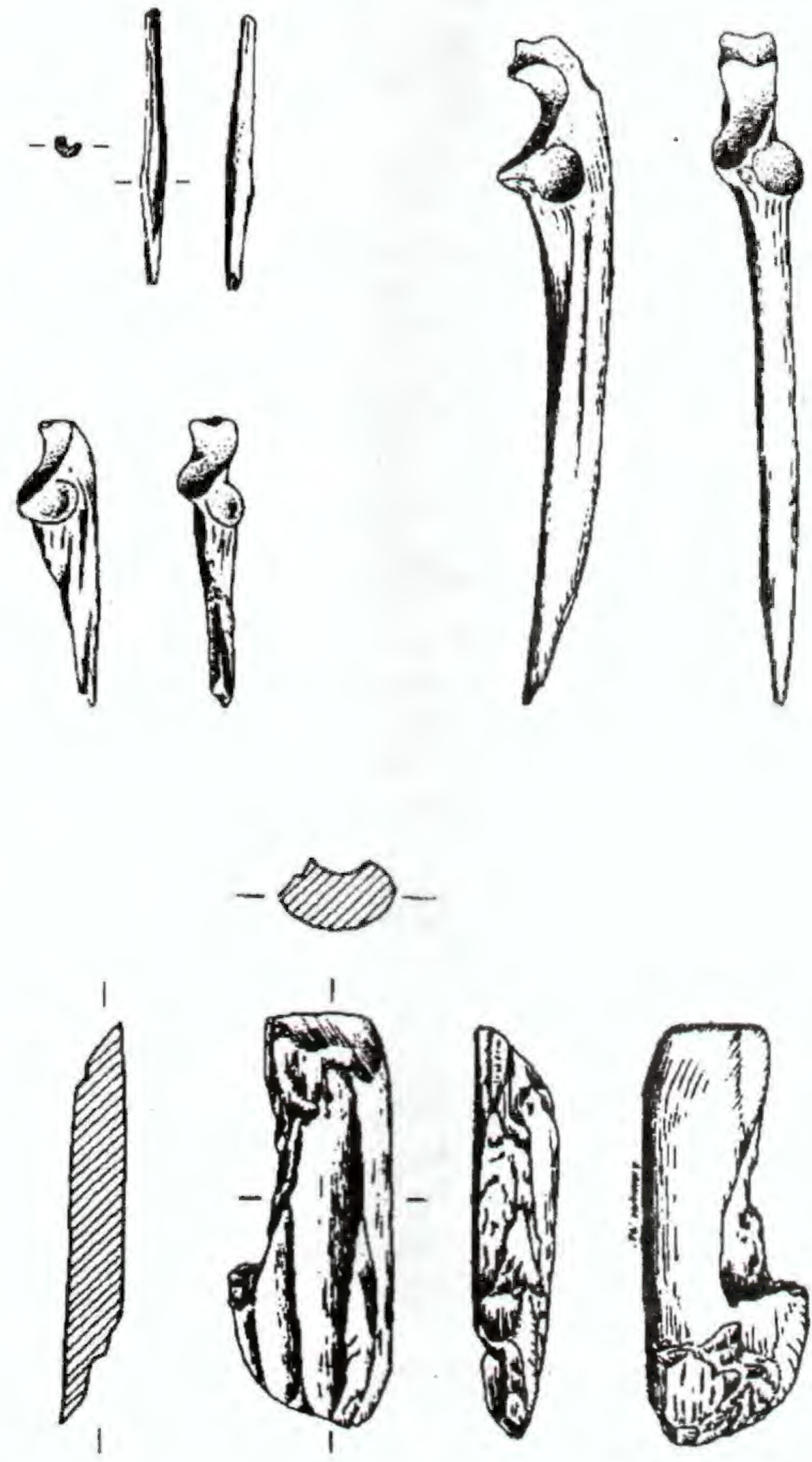

Gambar 3. Lancipan dan Spatula Gua Braholo 


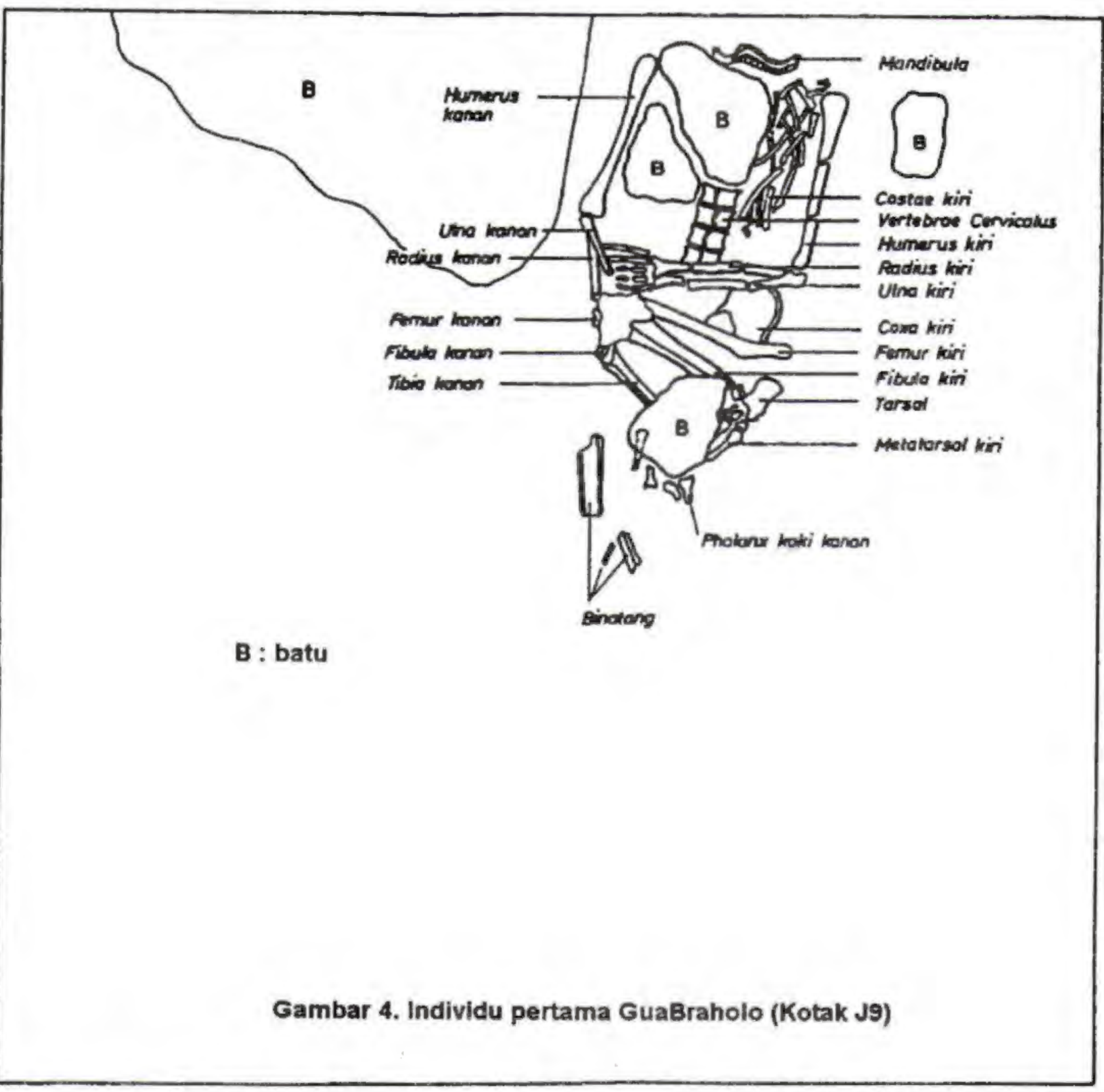

Berkala Arkeologi Th. XIX (I) 


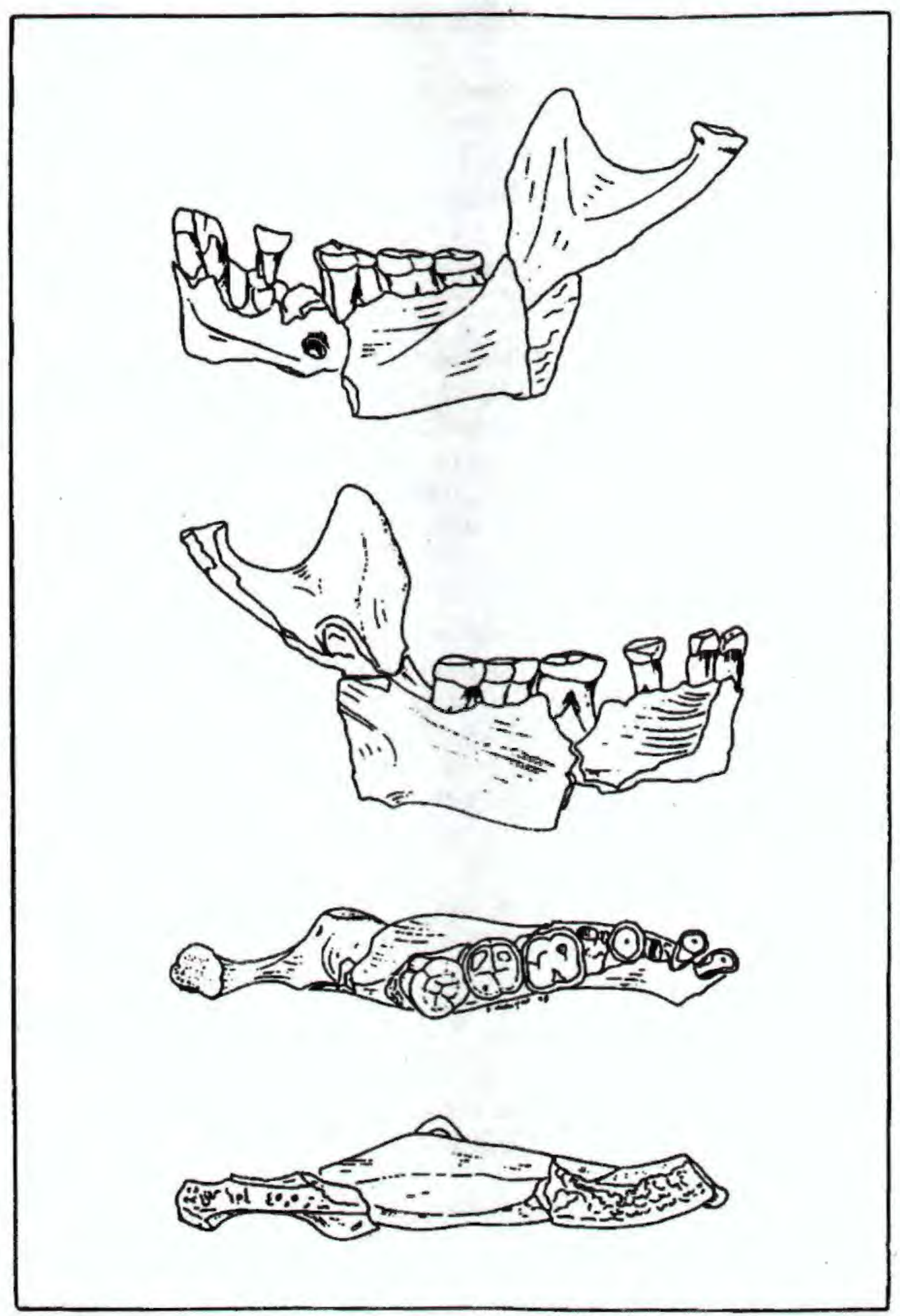

Gambar 6. Rahang bawah individu kedua Gua Braholo (Kotak L8) 